\title{
Vestibology
}

\section{Report from a Consensus Conference on the treatment of Ménière's disease with betahistine: rationale, methodology and results}

\author{
Risultati di una Consensus Conference sul trattamento della malattia di Ménière \\ con betaistina
}

\author{
A.P. CASANI ${ }^{1}$, G. GUIDETTI ${ }^{2}$, R. SCHOENHUBER ${ }^{3}$; THE CONSENSUS CONFERENCE GROUP \\ ${ }^{1}$ Department of Surgery and Medicine, Pisa University Hospital, Italy; ${ }^{2}$ Vertigo Center PCM, Modena, Italy; \\ ${ }^{3}$ Neurologist, Bolzano, Italy
}

\section{SUMMARY}

\begin{abstract}
Ménière's disease is a disorder of the inner ear that causes vertigo, tinnitus, fullness and hearing loss. Although several treatments are available, the success rate is reported to be around 70\%, similar to placebo. Betahistine, a weak H1 receptor agonist and an effective $\mathrm{H} 3$ receptor antagonist, is frequently prescribed for Ménière's disease, especially to reduce recurrent vertigo attacks. The effects of this drug on hearing and other audiological symptoms remains unclear. Given the inconclusive reports in the literature, we proposed a consensus conference on the use of betahistine in Ménière's disease. The aim was to define best practice criteria for therapy for Ménière's disease, improve clinical suitability and reduce heterogeneity of the therapeutic approach. The consensus conference on betahistine for Ménière's disease involved a group of Italian experts in vestibular disorders who were asked a series of questions prepared by opinion leaders. The Delphi method, an iterative investigation method, was used to increase consensus. Via a tele-voting system, each participant anonymously evaluated all statements using a Likert 5-point scale. Betahistine was considered useful for the treatment of dizziness and vertigo during the intercritical phase of the disease ( $87 \%$ agreeing answers). However, during the acute phase of the disease betahistine was considered less effective and useful only when associated with other drugs (71\% agreement). Similarly, the efficacy of the drug was considered low when used to reduce progressive hearing loss, tinnitus, and ear fullness. The experts advocated the use of betahistine during the intercritical phase of Ménière's disease to reduce the number and severity of vertigo attacks. Its use seems to be at low risk of major side effects.
\end{abstract}

KEY WORDS: Ménière's disease • Betahistine • Consensus Conference • Delphi method

\section{RIASSUNTO}

La malattia di Ménière è una patologia dell'orecchio interno che causa acufene, sensazione di ovattamento auricolare, ipoacusia e vertigini. Sebbene siano disponibili numerosi tipi di trattamento, il successo terapeutico è stimato intorno al 70\%, percentuale simile a quella riscontrata con l'utilizzo di placebo. La betaistina, un debole agonista dei recettori HI e un effettivo antagonista degli H3, è frequentemente prescritta nella malattia di Ménière. Non è chiaro di quanto la betaistina sia in grado di migliorare la sintomatologia nella Ménière. Data l'inconsistenza dei report presenti in letteratura, abbiamo proposto una Consensus Conference sull'utilizzo della betaistina nella malattia di Ménière. Lo scopo è stato definire i migliori criteri clinici dell'approccio terapeutico alla malattia di Menière, migliorarne l'appropriatezza clinica e ridurre l'eterogeneità delle prescrizioni. La Consensus Conference sull'utilizzo della betaistina ha coinvolto un gruppo di esperti italiani nelle problematiche dell'apparato vestibolare, a cui è stato chiesto di rispondere ad una serie di domande preparate da opinion leaders del settore. Allo scopo di aumentare la significatività del Consensus è stato utilizzato il metodo Delphi, una modalità d'indagine interattiva. Attraverso un sistema di televoto, ogni partecipante ha valutato in maniera anonima ciascun punto secondo una scala Likert a 5 punti. La betaistina è stata considerata utile nel trattamento dei capogiri e della vertigine durante la fase intercritica della malattia (87\% di concordanza nelle risposte). Tuttavia, durante la fase acuta della malattia la betaistina è stata considerata meno efficace e utile solo se associata ad altri farmaci (71\% di concordanza nelle risposte). Allo stesso modo, l'efficacia del farmaco è considerata bassa quando utilizzata per contrastare la perdita progressiva dell'udito, l'acufene e la sensazione di ovattamento auricolare. In conclusione, gli esperti hanno concordato nel supportare l'uso della betaistina durante la fase intercritica della malattia di Ménière allo scopo di ridurre il numero e la severità delle crisi vertiginose.

PAROLE CHIAVE: Malattia di Ménière • Betaistina $\bullet$ Consensus Conference $\bullet$ Metodo Delphi

Cite this article as: Acta Otorhinolaryngol Ital 2018;38:460-467. http://dx.doi.org/10.14639/0392-100X-2035

(C) Società Italiana di Otorinolaringologia e Chirurgia Cervico-Facciale 


\section{Introduction}

Ménière's disease (MD) is an idiopathic pathological condition of the inner ear, most often unilateral, caused by endolymphatic hydrops, which leads to symptoms such as fluctuating hearing loss, tinnitus and fullness, associated with recurrent episodes of rotational vertigo with neurovegetative symptoms ${ }^{1}$. The current prevalence of the disease is $190 / 100,000^{2}$. There is discordance regarding the gender-distribution of the disease: some authors report a higher prevalence in men ${ }^{3}$, while others described a higher prevalence in women ${ }^{4}$; there is general agreement that MD is a disease of middle-age, with average age at onset in the fourth decade of life ${ }^{2}$. A controversial feature of the disease is represented by possible bilateral involvement, especially during the natural progression of MD. The literature on this aspect provides extremely heterogeneous data, with percentages of bilateral involvement ranging from $2 \%$ to $78 \%$ of patients ${ }^{5}$. This broad range might depend on the definition of bilateral involvement, given that hearing abnormalities, without the appearance of complete symptomatology of MD, are frequently found in the contralateral ear ${ }^{6}$.

Various treatment strategies have been proposed and used for MD, most of which are based on empirical criteria. Some of these therapies are widely accepted, while others are only practiced in a few centres. The differences in treatments is due to the lack of a definite aetiopathogenesis of the disease, as well as to the difficulty of carrying out clinical class A studies, given the natural fluctuation of the disease which includes long phases of remission. Reviews that analyse the response of MD patients to various therapies have reported that the success rate, roughly $70 \%$, was not different from that obtained with placebo treatments ${ }^{7}$. Nevertheless, based on clinical pragmatism, medical treatment is the first therapeutic option for MD, taking into account cost-effectiveness and potential side effects. If a positive response to therapy is not obtained, more specific treatments may be considered. Medical treatment for MD has two components: treatment of acute attacks and prophylaxis between attacks. In the treatment of acute vertigo attacks, vestibular suppressants (i.e. dimenhydrinate, meclizine) are usually associated with antiemetic drugs. Diazepam, which has an additional beneficial anxiolytic effect, might also be administered intravenously. Steroid treatment in the acute phase, initially suggested because of the hypothesised autoimmune origin of $\mathrm{MD}$, has been used to reduce the magnitude of crises as well as to promote auditory and vestibular recovery ${ }^{8}$. Corticosteroids (e.g. prednisone $1 \mathrm{mg} / \mathrm{kg}$ ) can be used both intravenously and orally in cycles of 10-14 days. Finally, osmotic diuretics (10\% mannitol or glycerol) given intravenously as a slow infusion may also be used as treatment.

Treatment prescribed for the intercritical phase aims to: (i) reduce the number and severity of vertiginous crises; (ii) relieve chronic symptoms (instability and tinnitus); and (iii) prevent progression of the disease, with specific focus on hearing loss and loss of equilibrium. Maintenance therapies are able to achieve sufficient control of vertiginous crises in at least two-thirds of patients, especially when associated with a healthy lifestyle (i.e., no alcohol, no tobacco, no coffee, no stress), dietary measures (sodium restriction) and diuretics ${ }^{9}$; however, there is no effective therapy for long-term hearing preservation.

The most widely used drug for MD in Europe is betahistine, a histamine-like molecule that acts as a weak agonist for the $\mathrm{H} 1$ receptor and, at the same time, as an effective antagonist for the $\mathrm{H} 3$ receptor ${ }^{10}$. Betahistine was first registered in 1968 and is widely used in the management of vertigo. Although its mechanism of action is only partially known, several different potential effects based on both preclinical and clinical studies have been suggested. Firstly, betahistine modulates histaminergic neurotransmission through partial agonist action at the histamine $\mathrm{H} 1$ receptor, combined with potent histamine H3 antagonistic properties. Secondly, betahistine has been reported to have vascular effects in both the cochlea and brain ${ }^{11-14}$. Thirdly, betahistine is thought to have effects on neuronal excitability, with a dose-dependent inhibiting effect on spike generation of neurons in lateral and medial vestibular nuclei ${ }^{15}{ }^{16}$. It is possible that the anti-vertigo activity of betahistine is first achieved by the drug itself, and then sustained by aminoethylpyridine, one of its metabolites ${ }^{17}$. Finally, the available evidence suggests that the histamine $\mathrm{H} 3$ receptor plays a key role in vestibular compensation, behavioural recovery and reduction of symptoms. Betahistine may potentially act on recovery mechanisms to provide clinical benefits by helping to improve behavioural adaptation ${ }^{10}$. Taken together, these properties are thought to contribute to the beneficial therapeutic effects of betahistine in MD and vestibular vertigo. Although the effect of betahistine on vertigo has been assessed in many studies, it remains uncertain to what extent the compound improves symptomatology in MD and vestibular vertigo. In the past decade, only one systematic review ${ }^{18}$ and one meta-analysis ${ }^{19}$ were published on this topic, showing no strong evidence about the positive effects of betahistine MD. These inconclusive findings might be attributable to the methodology chosen to perform the analysis ${ }^{20}$. Thus, there is not sufficient evidence for any 
of the proposed treatments for the management of MD to be considered effective, and although several studies have been conducted, the results are inconclusive and inconsistent ${ }^{21}$.

\section{Methods}

In order to define adequate best practice criteria in MD therapy, we began with a rigorous and systematic analysis of the literature, identifying all studies on betahistine in MD. We evaluated the statistical methodology, selection criteria of patients, searching for possible biases, and determined whether a possible conflict of interest was present. Since most of the studies on betahistine were biased or inconclusive, we decided to consider expert opinion as the method of choice for clinical decision, organising a Consensus Conference (CC) with experts in the field. A $\mathrm{CC}$ is a series of meetings to collect opinions and decisions on new or controversial topics in science, technology and ethics, and is a useful and effective tool to synthesise current knowledge and address uncertainties ${ }^{22}$.

The CC on betahistine in MD involved a group of 78 Italian experts on vestibular disorders (see appendix), who were asked a series of questions specifically prepared by 13 opinion leaders. The opinion leader group (research team) consisted in Otolaryngologists or Audiologists with special expertise in Ménière's disease. After the questions had been formulated, selected articles were circulated to all participants, who reported their comments on a form. For each, two separate experts prepared respective statements. For controversial issues, for which no answer was found in the literature, new statements were prepared and discussed.

\section{Delphi method and statement generation}

To increase consensus, the CC was based on the Delphi method ${ }^{23}$. The Delphi method is an iterative investigation method, which through several stages of evaluation aims to reach the most comprehensive opinion, shared in a single statement; the Delphi method allows to systematically obtain responses to a problem from a panel of independent experts in two or three rounds with a consensus-based approach. After each round, an administrator provides a summary of the experts' answers and their rationale. The process ends when the experts' answers vary only slightly between rounds. Starting from the above-mentioned systematic review of the literature, the opinion leader group created for the panelists, relevant statements about specific scenarios associated with the employment of betahistine in Ménière's disease.

During the $\mathrm{CC}$ event (single day meeting in Rome on December $12^{\text {th }}$ 2015), a tele-voting system allowed each participant to anonymously evaluate all statements on a Likert 5-point scale. The answers associated with 1 and 2 of the scale were considered as a "NO", while 3, 4 and 5 were counted as "YES". Following the literature on the Delphi method, a statement was considered accepted when $70 \%$ agreement on "YES" or on "NO" was reached. Figure 1 show the process of acquisition of data from the $\mathrm{CC}$.

\section{Results}

The entire panel of 78 Italian experts in vestibular disorders participated in the $\mathrm{CC}$ and evaluated the use and efficacy of betahistine in MD. With regards to prevention of vertigo spells, betahistine was considered useful ( $87 \%$ agreement) and a first-choice therapy between attacks ( $71 \%$ agreement, Fig. 2). However, betahistine was considered less effective during the acute phase of the disease and useful only when associated with other drugs (77\% agreement, Fig. 3). In the management of Tumarkin's otolithic crisis, the drug was not considered efficacious ( $85 \%$ agreement), and useful only if associated with other agents (74\% agreement). When surveyed about Tumarkin's otolithic crisis, $66 \%$ of experts had not found a useful dosage and did not rely on betahistine monotherapy to deal with this condition. The efficacy of the drug is low when used to prevent progressive auditory deterioration (82\% agreement), tinnitus (79\% agreement) and fullness ( $86 \%$ agreement).

Despite the statement affirming that betahistine is not useful during the acute phase, if the drug is used in this phase of the disease, the dosage range is between 32 and $48 \mathrm{mg} /$ day (72\% agreement, Fig. 4). On the contrary, $86 \%$ of experts agreed on the usefulness of the drug in the intercritical phase. While $81 \%$ of experts agreed that the dosage can vary during the different phases of the disease, the preferred overall dosage was between 32 and $48 \mathrm{mg}$ /day

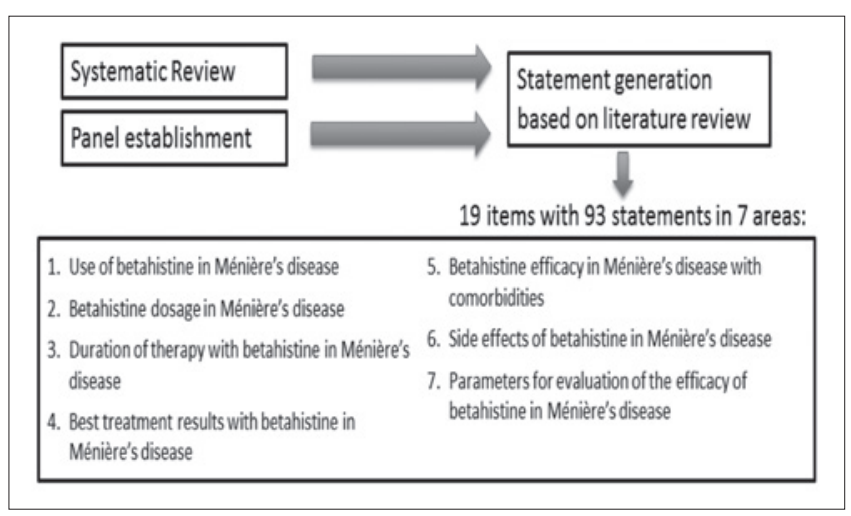

Fig. 1. Process used to select and achieve consensus for statements about betahistine in Ménière's disease. A number of statements were combined together for clarity, after the Consensus Conference. 


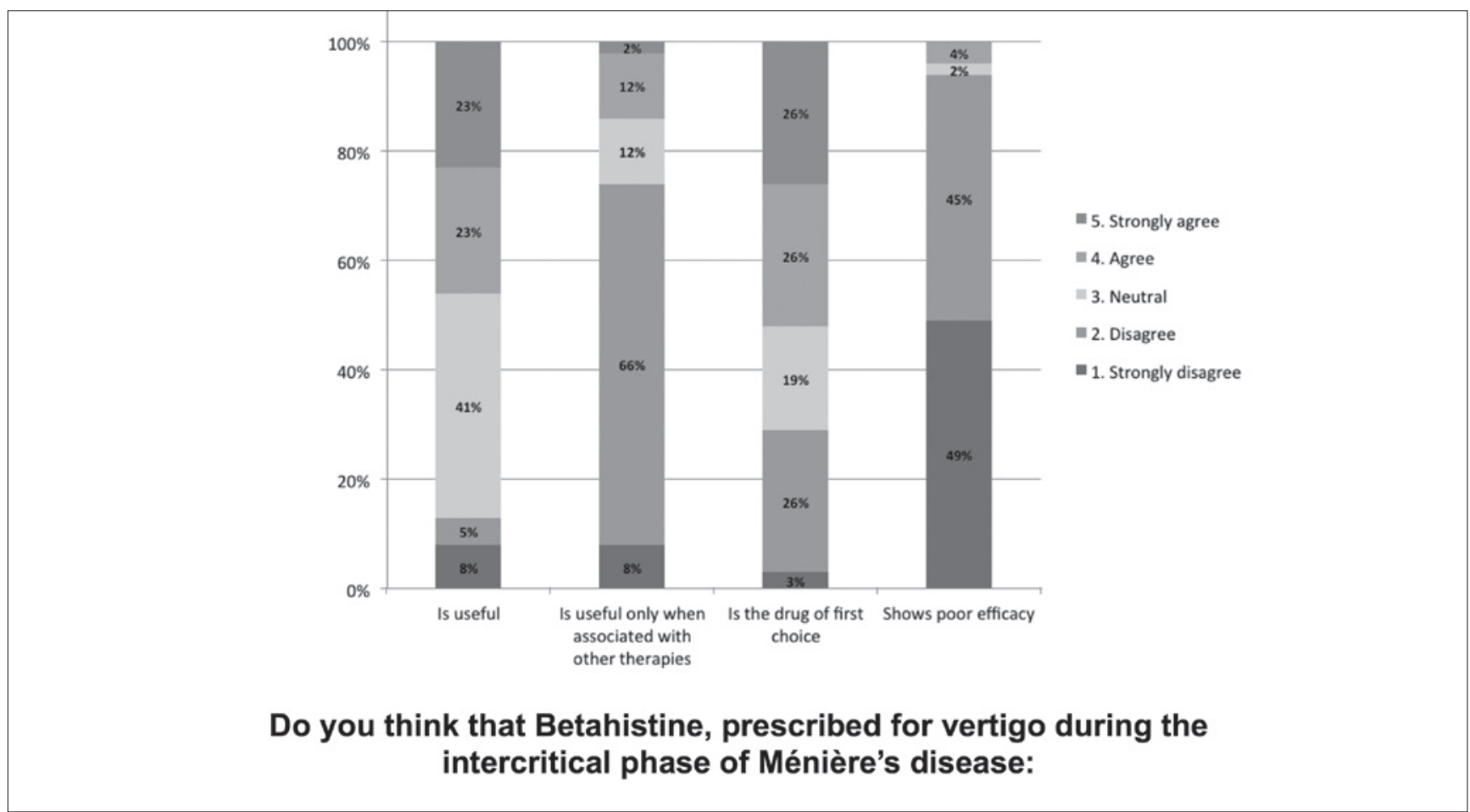

Fig. 2. Consensus conference on the use of betahistine in Ménière's disease: statements on the efficacy in the intercritical phase.

( $84 \%$ agreement, Fig. 5). The experts were also surveyed about the duration of treatment in relation to the number of Ménière's crises during a 6-month interval. The experts agreed on a 3-month treatment in cases of one to three crises per 6 months ( $82 \%$ agreement), while the preferred duration of treatment is 6 months (74\% agreement) if a

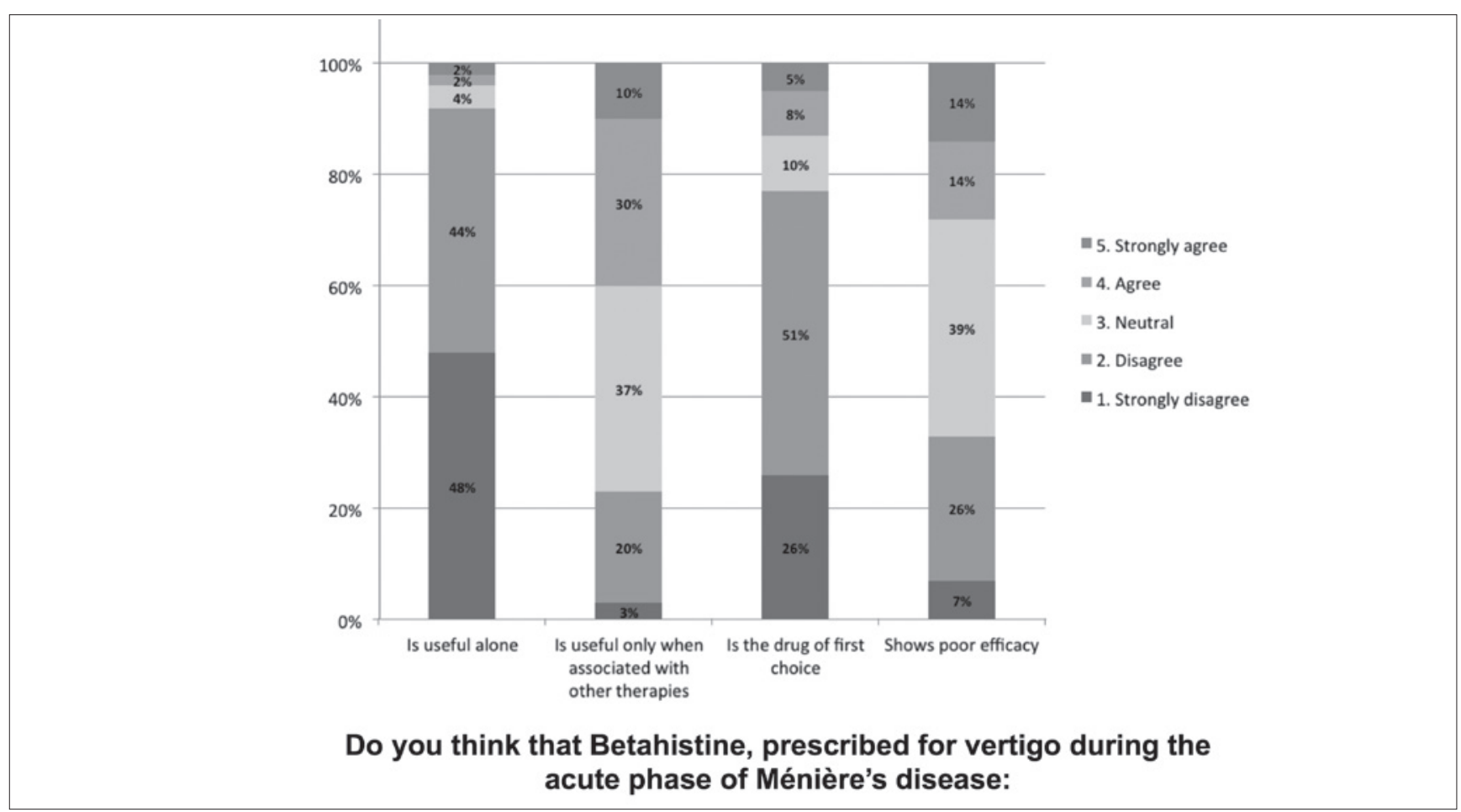

Fig. 3. Consensus conference on the use of betahistine in Ménière's disease: statements on the efficacy in the acute phase. 


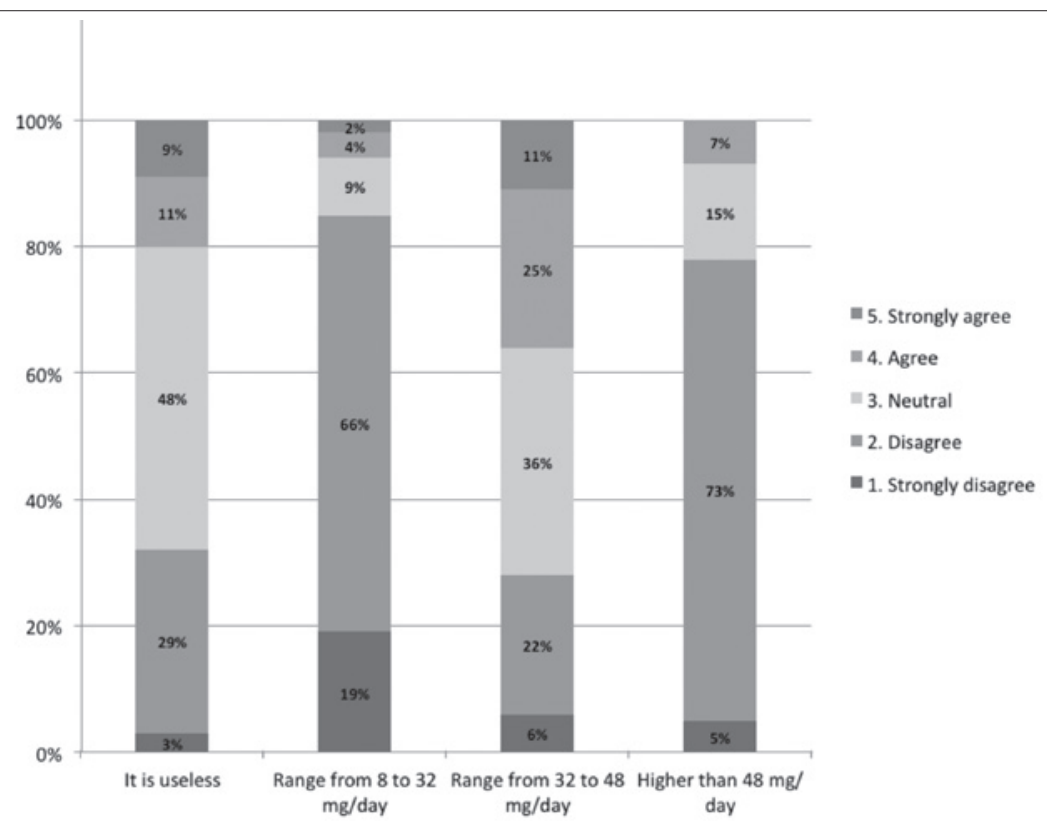

If you consider betahistine to be effective during the acute phase of Ménière's disease, what is the optimal dosage?

Fig. 4. Consensus conference on the use of betahistine in Ménière's disease: statements on optimal dosage in the acute phase.

patient has 4 to 10 crises in 6 months. In cases with more than 10 crises, the appropriate duration of treatment was considered to be either 6 months (69\% agreement) or one year (66\% agreement). The efficacy of betahistine does not seem to depend on age: $84 \%$ of experts agreed that it can be used by adults of all ages indifferently and regard-

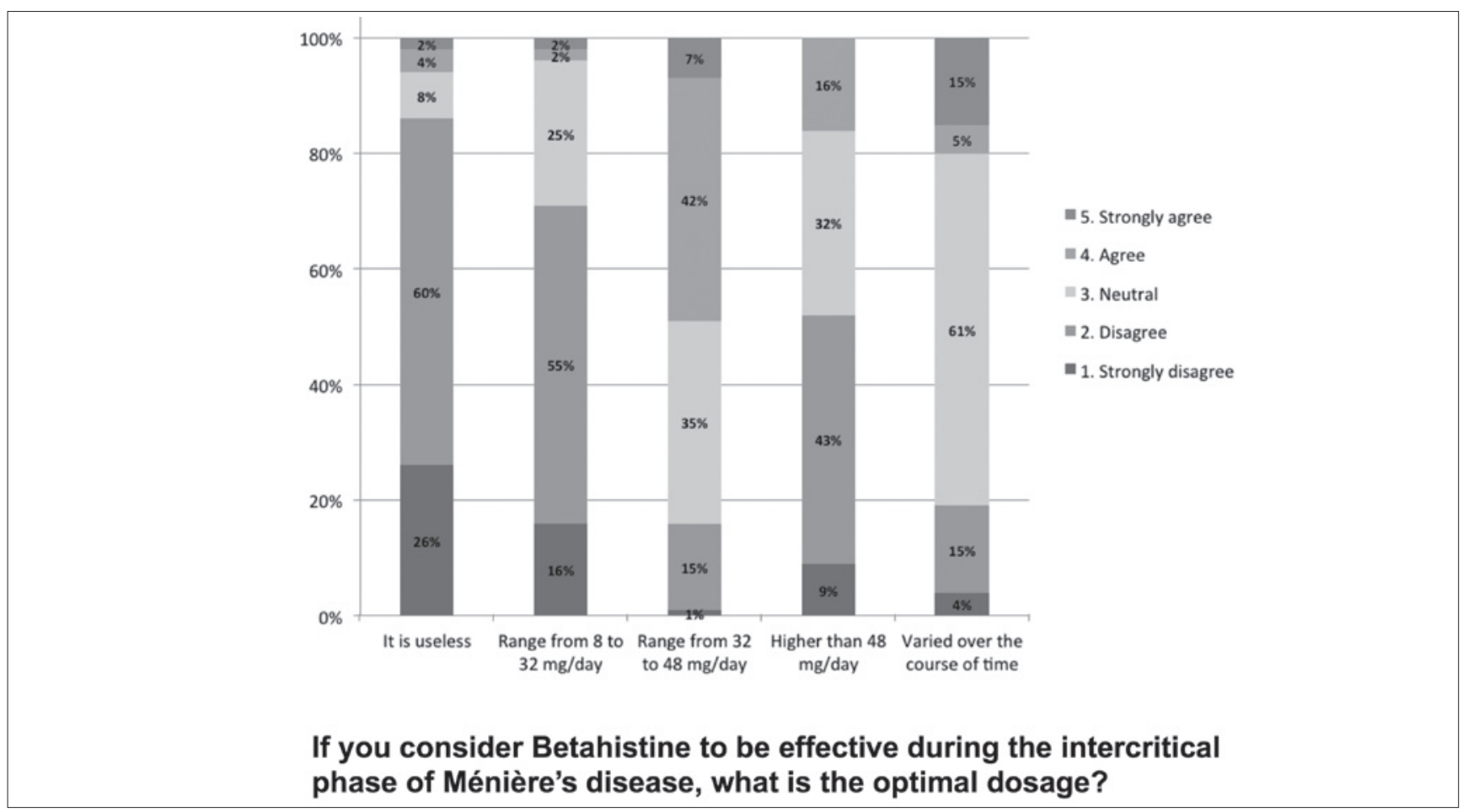

Fig. 5. Consensus conference on the use of betahistine in Ménière's disease: statements on optimal dosage in the intercritical phase. 
less of gender. As far as comorbid conditions and drug interactions are concerned, in patients with MD and migraine most of the experts surveyed would use betahistine in association with an anti-migraine drug (67\% agreement). In cases of comorbidity with anxious-depressive disorders, betahistine can be given in association with an anti-depressant or anxiolytic (78\% agreement). Betahistine was considered to be a safe drug, with the overall frequency of side effects judged to be less than $10 \%$ (90\% agreement). Gastric disturbances are the only common side effects mentioned by patients ( $73 \%$ agreement). Overall, to evaluate the efficacy of betahistine, the experts took into account the number and severity of crises in the preceding 6 months (93\% agreement), clinical assessment of the vestibule (67\% agreement) and the patients' quality of life ( $85 \%$ agreement).

\section{Discussion}

As previously discussed, the therapeutic strategies used for MD are varied and largely based on empirical criteria. The absence of a confirmed aetiopathogenesis, the difficulty in making a reliable diagnosis, together with the complexity of conducting clinical class A studies, explain the observed differences in treatments. In Europe, the most frequently prescribed drug, used mainly to reduce the frequency and severity of MD attacks, is betahistine, a weak $\mathrm{H} 1$ agonist and strong $\mathrm{H} 3$ antagonist histaminergic molecule ${ }^{10}$. Betahistine seems to have a dose-dependent role on neuronal excitability ${ }^{15}{ }^{16}$, as well as on cochlear and cerebral blood flow ${ }^{11-14} 24$. In addition, its effects on $\mathrm{H} 3$ receptors seem to have a key role on vestibular compensation, favouring recovery and reduction of residual symptoms ${ }^{25}$.

Recent literature on the efficacy of betahistine in MD appears to be very discordant, and there is a marked lack of systematic reviews and meta-analyses. A recent Cochrane review concluded that betahistine is an acceptable treatment ${ }^{18}$. However, the authors did not find strong evidence for the efficacy of the drug in management of dizziness, tinnitus, loss of hearing, or fullness in MD. In contrast, a meta-analysis carried out by Della Pepa et al. ${ }^{19}$ found a role for the drug in the management of dizziness. According to a more recent meta-analysis, this lack of unequivocal evidence could be due to methodological limitations ${ }^{20}$. In that study, the authors concluded that betahistine can be considered as a safe drug, with a positive benefit/risk ratio, being effective in diseases for which dizziness and vertigo are the main symptoms. The consensus of experts consulted on betahistine, in light of their clinical practice and daily management of patients with $\mathrm{MD}$, revealed a constant use of the drug during the intercritical phase, especially in monotherapy. Betahistine is considered to be safe, suitable for all age groups and associated with a low incidence of side effects (mainly gastrointestinal symptoms). These statements, based exclusively on the clinical experience of the consensus conference participants, seems to be confirmed by a very recent Cochrane review suggesting some positive effects of betahistine in reducing vertigo symptoms without any significant side effects ${ }^{26}$. Moreover, betahistine is successfully used with other drugs in cases of comorbidity with migraine and anxiety-depressive disorders ${ }^{27-30}$. During the intercritical phase, the dosage depends on the patient's response and phase of disease, but usually ranges from 32 to $48 \mathrm{mg} /$ day. The duration of treatment varies, according to the frequency of crises, from a minimum of 3 months up to a maximum of 1 year. Clinical vestibular evaluation (history and symptoms of vestibular dysfunction) and the patient's quality of life during the disease are also taken into account when evaluating the efficacy of betahistine. Betahistine is not recommended for the acute phase of MD or for Tumarkin's otolithic crises (although it can have a role if associated with other drugs), and has been found to have low efficacy in the management of auditory deterioration, tinnitus and auricular fullness.

\section{Conclusions}

The experts' clinical practice and personal experience support the use of betahistine in MD to reduce the number and severity of vertiginous crises, particularly during the intercritical phase of the disease. Betahistine does not show positive effects on auditory symptoms of MD, but its use seems to be at low risk of major side effects. However, clinical studies based on rigorous methodologies and outcome measures are needed to clearly evaluate the role of betahistine in the treatment of MD.

\section{Acknowledgements}

The authors thank Prof. Albera Roberto, Dr. Comacchio Francesco, Dr. Mandalà Marco, Dr. Manfrin Marco, Dr. Marcelli Vincenzo, Dr. Messina Aldo, Prof. Neri Giampiero, Prof. Nuti Daniele, Dr. Teggi Roberto and Paolo Vannucchi for their cooperation in preparing the statements presented in the Delphi Method.

Funding: this study was conducted by an unconditional support from Mylan. 


\section{Conflict of interest statement}

None declared.

\section{References}

1 Oberman BS, Patel VA, Cureoglu S, et al. The aetiopathologies of Ménière's disease: a contemporary review. Acta Otorhinolaryngol Ital 2017;37:250-63.

2 Alexander TH, Harris JP. Current epidemiology of Ménière's syndrome. Otolaryngol Clin North Am 2010;43:965-70.

3 Watanabe I. Ménière's disease in males and females. Acta Otolaryngol 1981;91:511-4.

4 Wladislavosky-Waserman P, Facer GW, Mokri B, et al. Ménière's disease: a 30-year epidemiologic and clinical study in Rochester, Mn, 1951-1980. Laryngoscope 1984;94:1098-102.

5 House JW, Doherty JK, Fisher LM, et al. Ménière's disease: prevalence of contralateral ear involvement. Otol Neurotol 2006;27:355-61.

6 Perez R, Chen JM, Nedzelski JM. The status of the contralateral ear in established unilateral Ménière's disease. Laryngoscope 2004;114:1373-6.

7 Coelho DH, Lalwani AK. Medical management of Ménière's disease. Laryngoscope 2008;118:1099-108.

8 Antonio SM, Friedman R. Menière's disease. In: Jackler RK, Brackmann DE (eds.). Neurotology. Philadelphia: Elsevier; 2005. pp. 621-38.

9 Rauch SD. Clinical hints and precipitating factors in patients suffering from Ménière's disease. Otolaryngol Clin North Am 2010;43:1011-7.

10 Lacour M, van de Heyning PH, Novotny M, et al. Betahistine in the treatment of Ménière's disease. Neuropsychiatr Dis Treat 2007;3:429-40.

11 Laurikainen E, Miller JM, Nuttall AL, et al. The vascular mechanism of action of betahistine in the inner ear of the guinea pig. Eur Arch Otorhinolaryngol 1998;255:119-23.

12 Meyer JS, Mathew NT, Hartmann A, et al. Orally administered betahistine and regional cerebral blood flow in cerebrovascular disease. J Clin Pharmacol 1974;14:280-9.

13 Tomita M, Gotoh F, Sato T, et al. Comparative responses of the carotid and vertebral arterial systems of rhesus monkeys to betahistine. Stroke 1978;9:382-7.

${ }_{14}$ Unemoto H, Sasa M, Takaori S, et al. Inhibitory effect of betahistine on polysynaptic neurons in the lateral vestibular nucleus. Arch Otorhinolaryngol 1982;236:229-36.

15 Valli P. Betahistine reduces the resting firing rate of ves- tibular receptors in the frog. Acta Otolaryngol 2000 (Suppl 544):8-10.

16 Soto E, Chavez H, Valli P, et al. Betahistine produces postsynaptic inhibition of the excitability of the primary afferent neurons in the vestibular end organs. Acta Otolaryngol 2001;(Suppl 545):19-24.

17 Botta L, Mira E, Valli S, et al. Effects of betahistine metabolites on frog ampullar receptors. Acta Otolaryngol 2000;120:25-7.

18 James A, Burton MJ. Betahistine for Ménière's disease or syndrome (review). Cochrane Database Syst Rev 2001;1:CD001873.

19 Della Pepa C, Guidetti G, Eandi M. Betahistine in the treatment of vertiginous syndromes: a meta-analysis. Acta Otorhinolaryngol Ital 2003;26:208-15.

20 Nauta JJP. Meta-analysis of clinical studies with betahistine in Ménière's disease and vestibular vertigo. Eur Arch Otorhinolaryngol 2014;271:887-97.

21 Adrion C, Fischer CS, Wagner J, et al. Efficacy and safety of betahistine treatment in patients with Ménière's disease: primary results of a long term, multicentre, double blind, randomised, placebo controlled, dose defining trial (BEMED trial). BMJ 2016;352:h6816.

22 Candiani G, Colombo C, Daghini R, et al. Come organizzare una conferenza di consenso. www.snlgss.it/cms/files/ manuale_metodologico_consensus_0.pdf.

${ }^{23}$ Linstone HA, Turoff M (eds.). The Delphi method: techniques and applications. http://is.njit.edu/pubs/delphibook/index.html.

${ }^{24}$ Ihler F, Bertlich M, Sharaf K, et al. Betahistine exerts a dose-dependent effect on cochlear stria vascularis blood flow in guinea pigs in vivo. PLoS One 2012;7:e39086.

25 Lacour M. Betahistine treatment in managing vertigo and improving vestibular compensation: clarification. J Vestib Res 2013;23:139-51.

26 Murdin L, Hussain K, Schilder AG. Betahistine for symptoms of vertigo. Cochrane Database Syst Rev 2016;CD010696.

27 Teggi R, Gatti O, Sykopetrites V, et al. Association of cinnarizine and betahistine in prophylactic therapy for Ménière's disease with and without migraine. Acta Otorhinolaryngol Ital 2014;34:349-53.

28 Celestino D, Rosini E, Carucci ML, et al. Ménière's disease and anxiety disorders. Acta Otorhinolaryngol Ital 2003;23:421-7.

29 Goto F, Tsutsumi T, Ogawa K. Successful treatment of relapsed Ménière's disease using selective serotonin reuptake inhibitors: a report of three cases. Exp Ther Med 2014;7:488-90. 


\section{Appendix}

Panel participants at Consensus Conference on the Treatment of Ménière's disease with betahistine: Alessandrini Marco, Armato Enrico, Artesi Leonardo, Balzanelli Cristiano, Barbara Maurizio, Beghi Andrea, Bentivegna Lisa, Bolognini Alfonso, Boninsegna Marco, Botticchio Rosetta, Brafa Alessandra, Brandolini Cristina, Bruno Ernesto, Bufalo Alfonsina, Bulbarelli Maurizio, Buonpane Giuseppe, Califano Luigi, Caligo Giacomo, Carrozza Emanuele, Castellucci Andrea, Cena Manuele, Coletta Mariano, Conflitti Renato, Coppo Gianfranco, Coscarella Mariangela, Cozzolino Giovanni, Cutrera Barbara, Cutri Nicola, Da Col Maurizio, Damiani Sergio, De Angelis Alfonso, Del Colle Raffaele, Dello Monaco, Maria Letizia, Falco, Carlo Emilio,
Falcone Gianluca, Ferrari Giampiero, Ferraro Guglielmo, Filiberto Daniele, Galera Francesco, Gallo Andrea, Gamba Paolo, Gianformaggio Carlo, Ingria Federico, La Placa Giacomo, Lauletta Rocco, Lucisano Sergio, Luperto Paolo, Mandara Mario, Manna Valentino, Martorana Irene Manuela, Miele Carolina, MiloneVincenzo, Mininni Francesco, Mininni Sebastiano, Mohanna Marwan, Nola Giuseppe, Pace Antonio, Padovani Davide, Pantaleoni Marco, Patrizi Mario, Perdona' Antonia, Petrillo Francesco, Petrone Domenico, Pindozzi Simona, Poletto Elisabetta, Primerano Giovanni, Raguso Michele, Rinaldi Antonio, Rizzo Davide, Saginario Vittorio, Santucci Giuseppe, Scotto Di Santillo Leonardo, Sergi Gaetano, Spasiano Roberto, Tassoni Alessandro, Tondolo Enrico, Venticinque Luciano. 